\title{
Anchoring and eco-labeling effects on inference and preference judgments
}

Hanna Andersson, Ulla Ahonen-Jonnarth, Fredrik Bökman - University of Gävle, Sweden

A decision problem that we often face is making tradeoffs between different quality and traits among products. In this experiment, the aim was to study how an anchor in inference and preference judgment interact with an eco-labeled product and a product without eco-label.

When study anchoring, participants usually answer two questions (Tversky \& Kahneman, 1974). In the first question, the they are asked to make a comparative judgment, for example: Are the percentage of African countries in the United Nations higher than 10\% $(65 \%)$ ? In the second question, the participants make an absolute judgment: How many of the African countries, in percentage, do you thing is a member in the United Nations?

People are willing to pay a premium for eco labeled products (e.g., Salladaré, Brécard, Lucas, \& Ollivier, 2016), even if they prefer the conventional alternative (Sörqvist et al., 2013). Participant's environmental concern also has an impact, since people with a high environmental concern have been observed to be more susceptible towards the eco-label effect in indoor environments (Holmgren, Kabanshi, \& Sörqvist, 2017) and performance on a color discrimination task under a light source with an environmental friendly label (Sörqvist, et al., 2015).

\begin{tabular}{lllll}
\hline & \multicolumn{4}{c}{ Type of question } \\
\cline { 2 - 5 } & \multicolumn{3}{c}{ Inference } & \multicolumn{2}{c}{ Preference } \\
\hline Label & Eco-label & No label & Eco-label & No label \\
Anchor & 19.95 SEK & 56.95 SEK & 19.95 SEK & 56.95 SEK \\
& (Low anchor) & (High anchor) & (Low anchor) & (High anchor)
\end{tabular}

In the present experiment, we investigated if an anchor had an effect on both inference and preference questions with and without an eco-label. The result showed that the anchor had an effect on participants answers on both inference and preference questions. The label seems to have an effect on participants judgment in the inference questions but not in the preference questions. Participants' environmental concern did not interact with the eco-label but the high altruistic group answered higher than the low altruistic group in the high anchor condition.

When the label information and the anchor value are compared with the target for the judgment (i.e., price), it is supposed that there is a change in the accessible knowledge about the target, because judges compare the target with the anchor by testing the possibility that the target's value is equal to the anchor value (Strack, Bahnik \& Mussweiler, 2016).
The implicit numerical information may enhance the following numerical

In summary, the results from the study show a clear anchoring effect in both inference and preference judgments. We also found that there was an effect of eco-label. However, the effect of the eco-label was more prominent in inference judgment than in the preference questions.

inference

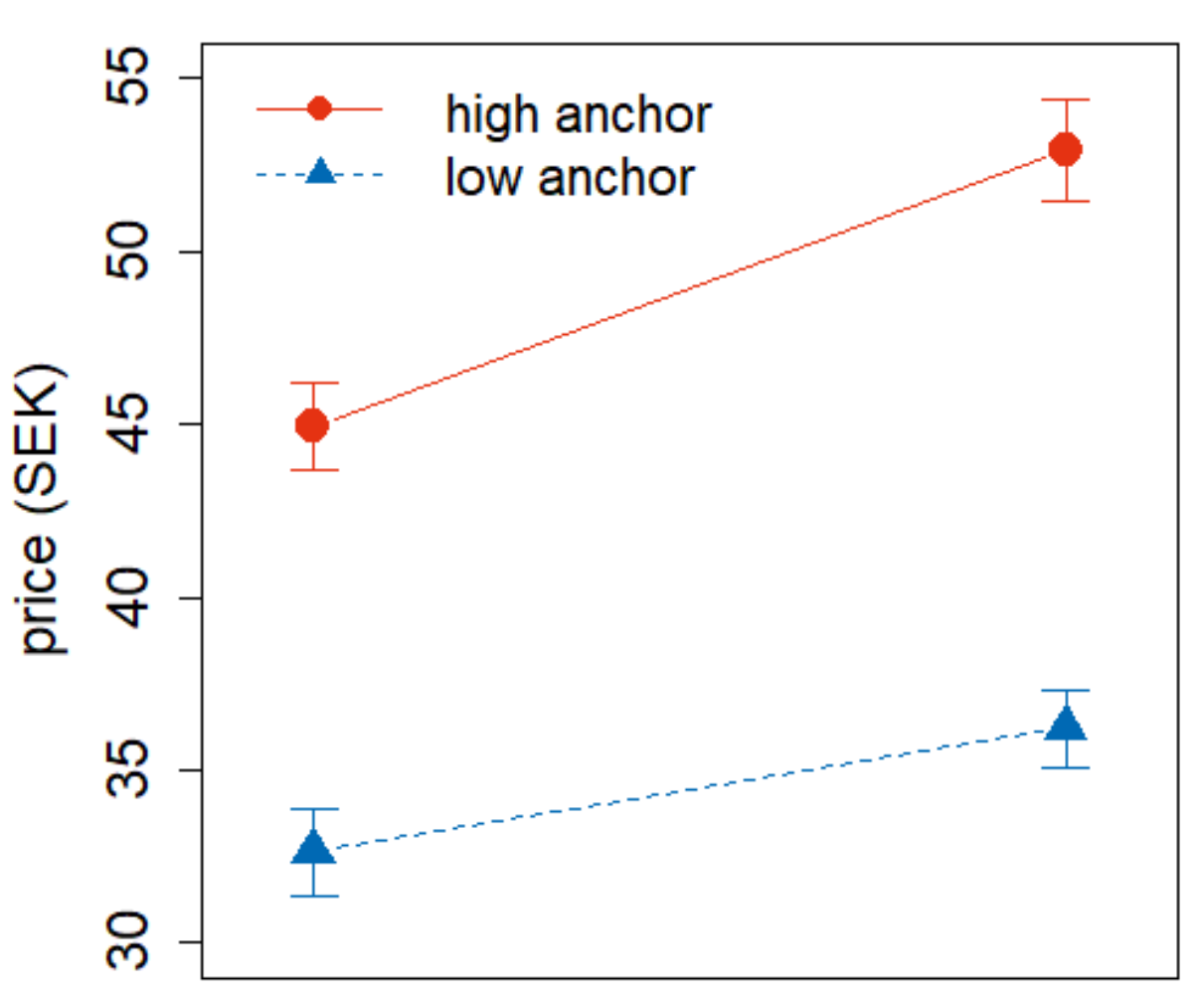

without eco-label judgment, and affect preference.

\section{References}

Holmgren, M., Kabanshi, A., \& Sörqvist, P. (2017) Occupant perception of "green" buildings: Distinguishing physical and psychological factors. Building and Environment, 114, 140-147.

Salladarré, F., Brécard, D., Lucas, S., \& Ollivier, P. (2016). Are French consumers ready to pay a premium for eco-labeled seafood products? A contingen valuation estimation wh heterogeneous anchoring. Agricultural Economics, 47(2), 247-258.

Strack, F., Bahnik, Š., \& Mussweiler, T. (2016) Anchoring: accessibility as a cause of judgmental assimilation. Current Opinion in Psychology, 12, 67-70.

Sörqvist, P., Hedblom, D., Holmgren, M., Haga, A. Langeborg, L., Nöstl, A., \& Kågström, J. (2013). Who needs cream and sugar when there is eco-labeling? Taste and willingness to pay for "eco-friendly" coffee. PloS one, 8(12), e80719.

Sörqvist, P., Haga, A., Langeborg, L., Holmgren, M., Wallinder, M., Nöstl, A., ... \& Marsh, J. E. (2015). The green halo: Mechanisms and limits of the eco-labe effect. Food quality and preference, 43, 1-9.

Tversky, A., \& Kahneman, D. (1974). Judgment under uncertainty: Heuristics and biases. Science, 185, 11241131. Annual review of psychology, 60, 53-85.

\section{preference}

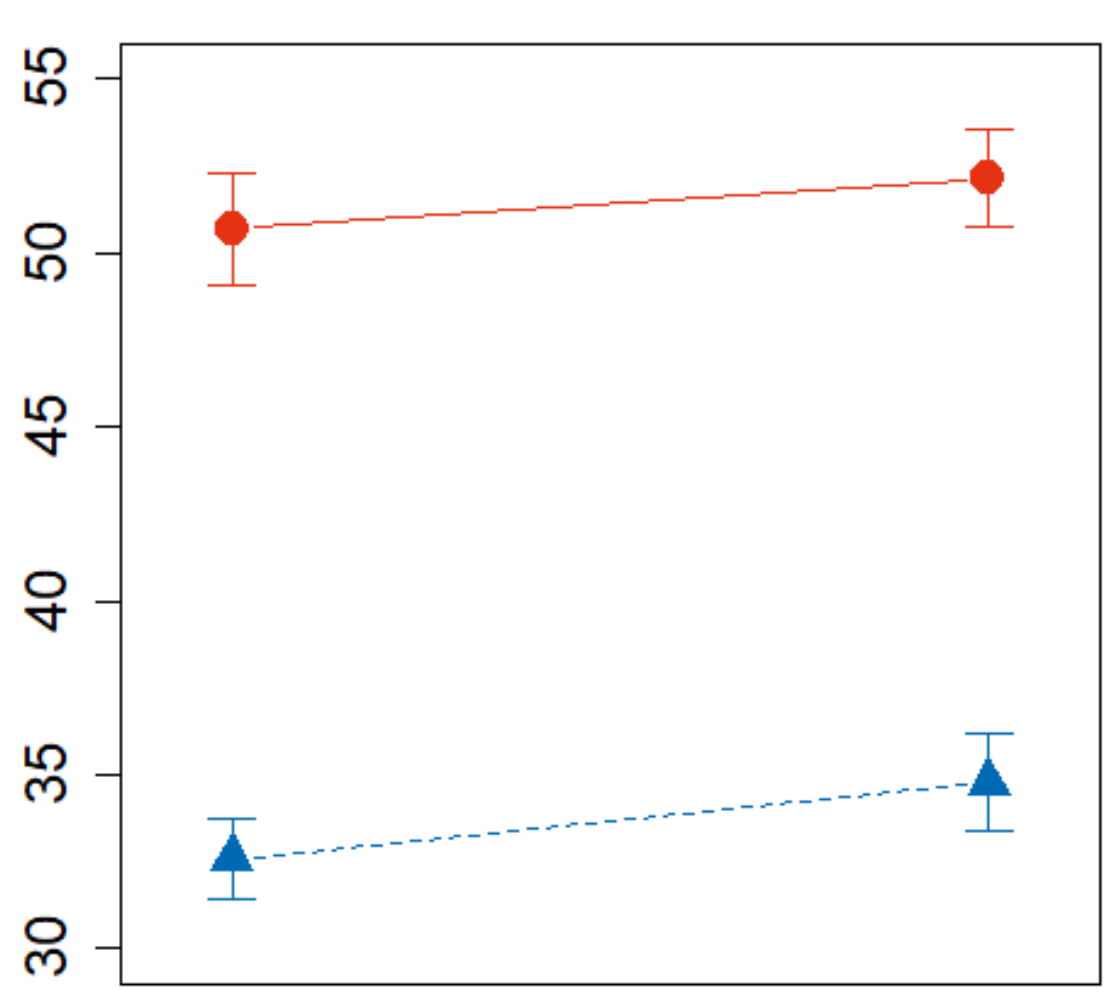

without eco-label 